\title{
A review of the addiction potential of energy drink-alcohol mix
}

\author{
Qin Xiang $\mathrm{Ng}^{1 *}$, Charlotte Hui Min Choo ${ }^{1}$ and Shawn Shao Hong Koh ${ }^{2}$ \\ ${ }^{1}$ Yong Loo Lin School of Medicine, National University of Singapore, Singapore \\ ${ }^{2}$ Faculty of Medicine, Nursing and Health Sciences Monash University, Australia
}

\begin{abstract}
The rapid growth of the energy drinks industry in the past decade demands a closer look at the inherent health risks and addiction potential of energy drink-alcohol mixes. More young adults are drinking energy drinks mixed with alcohol. Apart from the usual side effects of alcohol and caffeine when consumed individually, the mix of both substances reduces one's subjective level of alcohol intoxication, eventually leading to one drinking more alcohol than intended. Particularly, adolescents are found to be more vulnerable to these effects when exposed to the combination of caffeine and alcohol. We are of the opinion that energy drink-alcohol mixes are highly addictive and should be more tightly regulated. Recent studies show that caffeine-mixed alcohol has an adverse long-term desensitization effect on the intrinsic reward pathways in the brains of adolescent mice, suggesting that exposure to such drinks in adolescence may provide less pleasure and increase the likelihood of future substance abuse disorders. Alcohol dependence was also more likely in consumers of alcohol mixed with energy drinks. Societal education on the risks of caffeine-mixed alcoholic drinks and collaboration with these beverage companies should be the collective priority of public health specialists, health professionals and health regulatory authorities. Efforts should be targeted towards adolescents, who are the main consumers of these drinks and victims of the inherent health risks.
\end{abstract}

\section{Introduction}

Over the last decade, consumption of energy drinks became increasingly popular since the debut of Red Bull in 1997 [1]. A variety of products such as energy drinks, caffeine pills and caffeinated peanut butter is now easily accessible [2,3]. Of which, the most popular is highly caffeinated energy drinks, which are available in different brands, volumes and caffeine concentrations [3-7]. The caffeine content in energy drinks typically vary from 80 to $141 \mathrm{mg}$ per 8 ounces, equivalent to five ounces of coffee or two 12-ounce cans of caffeinated soft drink such as Mountain Dew or Coca Cola [8].

These caffeinated products are extremely popular among adolescents for mixing with alcohol [9]. For instance, Jägerbomb, which is a shot glass of Jägermeister dropped into a glass of Red Bull energy drink, is a well-received and popular party drink amongst youths. $23 \%$ to $47 \%$ of young adults consume such drinks $[10,11]$. Many of these adolescents consume large amounts of caffeine mixed alcohol for purposes of self-indulgence, such as increased amount of toxication and pleasure from it [12-13].

However, increased energy drink consumption has accounted for an increase in emergency department visits of two fold between 2007 and 2011 [2], bringing to attention the potential harms of exposure to highly caffeinated beverages to adolescents. While the consumption of energy drink itself can be potentially harmful, its negative health effects are further accentuated if mixed with alcohol [14].

We are of the opinion that energy drink-alcohol mixes have inherent addiction risks and should be more tightly regulated.

\section{Methods}

We hypothesize that the consumption of alcohol-mixed caffeinated energy drinks can alter the reward pathways of adolescents' brains more strongly than alcohol or caffeine alone, increasing one's susceptibility to the risk of addiction. To evaluate this hypothesis, a preliminary search on the PubMed, Google Scholar and ScienceDirect database using the keywords [alcohol OR ethanol] AND [caffeine OR stimulant OR energy drink] yielded 6,831 papers published in English between 1-Jan-1980 and 1-Aug-2016.

\section{Results and discussion}

Multiple studies have found that caffeine can possibly reduce one's ability to accurately assess the intoxicating effects of alcohol [15-19]. Participants who consumed alcohol mixed with energy drinks tend to report subjectively lower intoxication levels compared to those who consumed alcohol alone and with the same estimated blood alcohol concentration (eBAC) [17-19]. This could potentially lead to greater consumption of alcohol, further impairment in behavioural regulation and addiction in the long term.

A recent study on adolescent mice showed that repeated exposure to caffeine-mixed alcohol resulted in significant locomotor sensitisation, similar to chronic cocaine use [15]. Compared to alcohol or caffeine use alone, increased amounts of protein $\triangle$ FosB accumulate in the nucleus accumbens following repeated caffeine-mixed alcohol exposure [15]. The nucleus accumbens is intimately involved in reward associated learning and behaviours, particularly the development of substance use disorders. $\triangle$ FosB is an indicator of long-term neurochemical changes

Correspondence to: Qin Xiang Ng, Yong Loo Lin School of Medicine, 1E Kent Ridge Road, Singapore 119228, Tel: +65-9125-1908, E-mail: ng.qin.xiang@u.nus.edu

Key words: energy drinks, caffeine, alcohol, adolescent, risks

Received: January 18, 2017; Accepted: February 10, 2017; Published: February 13,2017 
and is elevated in abusers of serious drugs such as cocaine or morphine.

In another experiment, the same researchers studied if mice exposed to caffeine-mixed alcohol would consume more saccharine, an artificial sweetener. It was found that mice exposed to caffeinemixed alcohol during adolescence were desensitized to substances that give a pleasurable effect such as saccharine and would subsequently consume greater amounts of the substance. This points to altered reward pathways in the brain and desensitization in such a way that humans who are similarly exposed to caffeine-mixed alcohol would have a greater propensity towards substance abuse in adulthood [15].

Research on the causative neurotransmitter mechanisms behind the increased risk profile for energy drink-alcohol mix has been predominantly on adenosine and dopamine [19]. Adenosine is an inhibitory neurotransmitter in the brain. Being an adenosine antagonist, caffeine prevents the action of adenosine hence decreasing sedation and increasing stimulation. Meanwhile, the transmission of dopamine is inhibited by the activation of adenosine A2A receptors. As such, with reduced adenosine action in caffeine use, dopamine activity increases, resulting in greater drinking desires or levels.

A study conducted on university students analysed alcohol and energy drink use associated consequences [16]. Compared to days when students consumed only alcohol, they drank more alcohol drinks, reached a higher eBAC and spent more time drinking, on days they had alcohol mixed with energy drinks. This observation supports the concept of alcohol priming (as measured by increased desire to drink more alcohol that last for a longer duration of time), where the consumption of energy drinks may increase the drive to drink more alcohol [18]. Participants in the study also reported feeling more negative alcohol-related consequences [14]. According to another study, this is known as the "wide-awake drunk" state where the high dose of caffeine appears to reduce some of alcohol's sedative effects [19].

Studies on the long term effects of energy drink-alcohol mix consumption indicate that these consumers were more likely to be screened as alcohol dependent [20-22] as these consumers were unable to restrict their alcohol use, in terms of both frequency and amount consumed.

Collectively, these studies support our hypothesis that energy drink-alcohol mixes are addictive and adolescents are more vulnerable when exposed to the combined effects of caffeine and alcohol.

\section{Conclusion}

The increasing popularity of energy drink-alcohol mixes presents severe short and long-term risks of addiction and future substance abuse disorders. More research is needed to fully understand the effects such beverages have. Meanwhile, societal education on the risks of caffeine-mixed alcoholic drinks and collaboration with these beverage companies should be the collective priority of public health specialists, health professionals and health regulatory authorities. Efforts should be targeted towards adolescents, who are the main consumers of these drinks and the greatest victims of their risks.

\section{Acknowledgements}

The authors report no conflicts of interest. The authors alone are responsible for the content and writing of the article.

\section{References}

1. Malinauskas B, Aeby V, Overton R, Carpenter-Aeby T, Barber-Heidal K (2007) A survey of energy drink consumption patterns among college students. Nutr $J$ 6: 35 . [Crossref]

2. Arria AM, Caldeira KM, Kasperski SJ, Vincent KB, Griffiths RR, et al. (2011) Energy drink consumption and increased risk for alcohol dependence. Alcohol Clin Exp Res 35: 365-375. [Crossref]

3. Reissig CJ, Strain EC, Griffiths RR (2009) Caffeinated energy drinks--a growing problem. Drug Alcohol Depend 99: 1-10. [Crossref]

4. McLellan TM, Lieberman HR (2012) Do energy drinks contain active components other than caffeine? Nutr Rev 70: 730-744. [Crossref]

5. O'Brien MC, McCoy TP, Rhodes SD, Wagoner A, Wolfson M (2008) Caffeinated cocktails: energy drink consumption, high-risk drinking, and alcohol-related consequences among college students. Acad Emerg Med 15: 453-460. [Crossref]

6. Clauson KA, Shields KM, McQueen CE, Persad N (2008) Safety issues associated with commercially available energy drinks. J Am Pharm Assoc (2003) 48: e55-63. [Crossref]

7. Simon M, Mosher J (2007) Alcohol, energy drinks, and youth: A dangerous mix. San Rafael, CA: Marin Institute.

8. Pronsky Z, Crowe J (2010) Food medication interactions. (1st edn). Birchrunville, Penn.: Food-Medication Interactions.

9. (2013) Energy Drinks and Shots: U.S. Market Trends: Packaged Facts.

10. Brache K, Stockwell T (2011) Drinking patterns and risk behaviors associated with combined alcohol and energy drink consumption in college drinkers. Addict Behav 36: 1133-1140. [Crossref]

11. Oteri A, Salvo F, Caputi AP, Calapai G (2007) Intake of energy drinks in association with alcoholic beverages in a cohort of students of the School of Medicine of the University of Messina. Alcohol Clin Exp Res 31: 1677-1680. [Crossref]

12. Peacock A, Pennay A, Droste N, Bruno R, Lubman DI (2014) 'High' risk? A systematic review of the acute outcomes of mixing alcohol with energy drinks. Addiction 109: 1612-1633. [Crossref]

13. Marczinski CA (2014) Combined alcohol and energy drink use: hedonistic motives, adenosine, and alcohol dependence. Alcohol Clin Exp Res 38: 1822-1825. [Crossref]

14. Arria AM, O’Brien MC (2011) The "high" risk of energy drinks. JAMA 305: 600-601. [Crossref]

15. Robins MT, Lu J, van Rijn RM (2016) Unique Behavioral and Neurochemical Effects Induced by Repeated Adolescent Consumption of Caffeine-Mixed Alcohol in C57BL/6 Mice. PLoS One 11: e0158189. [Crossref]

16. Patrick ME, Maggs JL (2014) Energy drinks and alcohol: links to alcohol behaviors and consequences across 56 days. $J$ Adolesc Health 54: 454-459. [Crossref]

17. Marczinski CA, Fillmore MT, Bardgett ME, Howard MA (2011) Effects of energy drinks mixed with alcohol on behavioral control: Risks for college students consuming trendy cocktails. Alcohol Clin Exp Res 35: 1282-1292. [Crossref]

18. Ferreira SE, de Mello MT, Pompéia S, de Souza-Formigoni ML (2006) Effects of energy drink ingestion on alcohol intoxication. Alcohol Clin Exp Res 30: 598-605. [Crossref]

19. Marczinski CA, Fillmore MT (2006) Clubgoers and their trendy cocktails: Implications of mixing caffeine into alcohol on information processing and subjective reports of intoxication. Exp Clin Psychopharmacol 14: 450-458. [Crossref]

20. Marczinski CA, Fillmore MT, Henges AL, Ramsey MA, Young CR (2013) Mixing an energy drink with an alcoholic beverage increases motivation for more alcohol in college students. Alcohol Clin Exp Res 37: 276-283. [Crossref]

21. Attwood AS (2012) Caffeinated alcohol beverages: a public health concern. Alcohol Alcohol 47: 370-371. [Crossref]

22. Corbin WR, Gearhardt A, Fromme K (2008) Stimulant alcohol effects prime within session drinking behavior. Psychopharmacology (Berl) 197: 327-337. [Crossref]

Copyright: (C)2017 Xiang Ng Q. This is an open-access article distributed under the terms of the Creative Commons Attribution License, which permits unrestricted use, distribution, and reproduction in any medium, provided the original author and source are credited. 